\title{
Research on Aviation Control Vocational Education
}

\author{
Chunguang Wang ${ }^{a}$, Changjiang Sun ${ }^{b}$, Hangxing Zhou ${ }^{a}$, Xiujuan Liu ${ }^{\text {a,* }}$ \\ Beijing Institute of Technology, Zhuhai, School of Aviation, Zhuhai, 519088, China \\ aemail:723704537@qq.com, email:1244463196@qq.com \\ ${ }^{*}$ corresponding author
}

Keywords: Air traffic control; Vocational education; Training mode; Controllers

\begin{abstract}
With the continuous increase of flight flow, the demand for air traffic controllers is getting higher and higher, and the demand for training air traffic controllers is highlighted. How to cultivate talents to meet the needs of the rapid development of aviation is the key issue to promote the development of aviation control industry. From the perspective of vocational education, the author analyzes the existing problems in the vocational education of air traffic control in China, discusses the training mode and content of the vocational education of air traffic control, and puts forward the ways to implement the vocational education of air traffic control.
\end{abstract}

\section{Introduction}

In recent years, with the increasing demand for aviation services, the aviation industry has developed vigorously and the flight flow has increased continuously. In order to ensure good air order and flight safety, it is necessary to vigorously develop the aviation control industry. The demand for aviation control personnel training is highlighted. For a long time, the training of air traffic controllers in China has always been based on skill education. However, with the continuous improvement of social knowledge, the training of air traffic controllers has shifted from the traditional skill education to skill education and academic education, and the emphasis on academic education is still increasing, even exceeding the trend of skill education. Here, we focus on the vocational education of air traffic control.

\section{The Current Situation of Aviation Control Vocational Education in China}

At present, the training of air traffic controllers and dispatchers in China is mainly carried out in three civil aviation colleges, such as China Civil Aviation University, China Civil Aviation Flight College and Nanjing University of Aeronautics and Astronautics. It is mainly a traditional mode of college entrance examination enrollment and training, and a small number of " $4+1$ " students (i.e. four-year undergraduate students from other colleges and universities After graduation, 1 years of training or control).With the rapid development of air transport industry, it is urgent to establish and have a large number of high-quality air traffic controllers. Since 2000, with the continuous improvement and renewal of control equipment, the continuous transformation and innovation of control concepts, the application of new technologies and the increasing demand for airspace, especially after the opening of low-altitude airspace, the overall quality of controllers has become increasingly demanding. Over the years, civil aviation has spent manpower and material resources on training air traffic controllers, and has devoted itself to studying more advanced, scientific, thorough and effective personnel training and improvement programs. In the past, the training method of air traffic controllers was a simple way of tutoring and apprenticeship. Through listening to the explanations and demonstration of senior controllers, plus the study of their own basic theoretical knowledge, and then to the actual work to slowly understand and master. At present, this kind of training method is far from meeting the needs of air traffic control. It is necessary to use advanced training management mode to carry out all-round vocational quality, vocational skills education and training for air traffic controllers. 


\section{Characteristics of Air Traffic Control and Requirements for Talents}

\subsection{Characteristics of Air Traffic Control Posts.}

The main task of air control is to ensure the safe and orderly flow of aircraft in the air and on the ground in accordance with certain rules, and to provide related services. Air traffic control is a challenging profession. The work of air traffic control is accomplished by accurate, fast, agile thinking, accurate language expression and exquisite command technology. It not only has the objective laws of natural science (such as the use of aircraft performance, meteorology and other scientific knowledge), but also has the technical skills of engineering technology (the deployment of flight conflict technology, the use of conversation, etc.[1]), reflecting the unity of science and art.

\subsection{Requirements for Air Traffic Control Professionals.}

First, the basic qualities that a controller should possess. Mainly including the nature of air traffic control work determines that the controller must have a high sense of responsibility, rigorous style of work, strict sense of discipline, excellent control knowledge and technology, as well as a good psychological quality and mentality[2].

Second, the ability of controllers in practical work. Mainly is the number of resolution and memory, spatial three-dimensional thinking ability, language expression ability, future trend prediction ability, decision-making ability, emotional and mental self-control ability, emergency response ability, coordination ability and work order and energy distribution [3].

\section{Problems in China's Aviation Control Vocational Education}

At present, whether undergraduate education or postgraduate education, China's controller training mode is fundamentally academic education plus vocational skills education, and there is a clear distinction between the two, and vocational skills education is too short and the effect is not obvious.

First, the number of air traffic controllers for civil aviation and civil aviation is relatively small. At present, there are only 6000 controllers in our country. Facing the increasing pressure of air safety management, it is impossible to become a powerful aviation country without enough controllers.

Second, the quality of aviation control personnel training is uneven, which directly affects the quality of training. There are certain differences in the source of personnel training between civil aviation and civil aviation control system. Civil aviation air traffic controllers undergraduate degree on the basis of professional training, and many of the military air traffic controllers from grounded students transferred, flight students and other engineering and technical students in the enrollment conditions are different, resulting in the military air traffic control personnel training level gap is larger.

Third, the quality of aviation controllers can not be fully integrated with international standards. Aviation is an international industry, and every link of aviation operation has a strong international color. The training of air traffic controllers must conform to international quality standards, such as standard English land-air communication, international common control skills and so on. These international standards are unified by ICAO. The internationalization of educational standards needs to be realized through the internationalization of curriculum education and educational assessment standards. Our military civil aviation control vocational education has great deficiencies in this respect.

Fourth, the quality of aviation controllers can not be fully integrated with international standards. Aviation is an international industry, and every link of aviation operation has a strong international color. The training of air traffic controllers must conform to international quality standards, such as standard English land-air communication, international common control skills and so on. These international standards are unified by ICAO. The internationalization of educational standards needs to be realized through the internationalization of curriculum education and educational assessment standards. Our military civil aviation control vocational education has great deficiencies in this respect. 
Fifth, there is not enough investment in training qualified personnel. In the past, civil aviation investment focused only on airports, aircraft, equipment, and very limited investment in the training of controllers and dispatchers. Each student spends about 3,000 yuan a year, or 12,000 yuan in four years, the equivalent of 40 hours in the UK. Although equipped with air traffic control simulator, the update and maintenance of the equipment are not timely. The number of training hours for controllers is small, only 150 hours, far below the International Civil Aviation Organization (ICAO) requirements of 340 hours, it is difficult to compete for high-intensity radar control work. The same problem exists in the training of staff of the air force.

Overall, China's air traffic control system from the technical facilities are not advanced enough, there are many drawbacks in the system and management, and there is a lot of room for improvement. After the opening of low altitude airspace, the aviation control industry has entered an unprecedented period of development opportunity. We should make great efforts to seize this important opportunity period, earnestly study the contents, modes, methods and educational implementation ways of air traffic control personnel training, overcome the drawbacks of the existing system and mode mechanism, actively reform the education system and management system, do a good job in top-level design, plan the construction path, and make the air traffic control industry It is full of youth.

\section{Training Mode and Content of Aviation Control Vocational Education}

\subsection{Training Mode.}

In training mode, we should break the single mode of academic education and gradually implement the vocational training mode of non-academic education.

The training mode of controllers in China should be combined with academic education and vocational education. Controller education is different from general higher education, mainly reflected in its vocational orientation education (mainly for air traffic control profession). Controllers should be technically qualified personnel, and from the point of view of the level of education of controllers, should belong to higher vocational education. Controller education should have the characteristics of higher education. It mainly solves the problem of the level of controller education, that is, it should have the characteristics of higher education. At the same time, the essential problem of controller education has been solved, that is, the goal of training is to train senior technicians who meet the needs of modern air traffic control.

\subsection{Contents of Education.}

First, ideological and moral education and professional ethics education. The training of the controllers should make them have a correct outlook on life and the world, have correct political beliefs and pursuits, and form professional ethics of loving posts and devoting themselves to work, being courteous and honest, and abiding by discipline and law.

Second, the cultivation of work style education. It is necessary for students to have a thorough understanding of the high-risk and high-responsibility nature of the work of the regulators, to strengthen the cultivation of their discipline, normativeness and enthusiasm while strengthening their theoretical study and professional guidance, so as to set up a good work style, to maintain a strong organizational concept and combat effectiveness in their work and to achieve self-restraint. And self-supervision.

Third, vocational skills training. Familiar with and master the operation process of the post, strengthen the training of the controllers' professional ability, strengthen the training of legal knowledge and management knowledge of the staff of the business departments of the organs and the leaders in charge of the front line of the control, shorten the pre-job adaptation period and train the talents efficiently.

Fourth, the cultivation of psychological quality. Control work has high risk and unexpected, the psychological quality of the controllers directly affects their ability to judge and make decisions in dealing with problems, especially for emergencies. In training, we should pay attention to the training of psychological quality of controllers [4]. On the one hand, it is necessary to establish and improve 
the selection mechanism of the controllers and select the personnel with good psychological qualities; on the other hand, it is necessary to strengthen the training of the psychological qualities of the controllers during the probationary period so as to adapt them to the particularities of the control work and adopt appropriate incentives and pressure measures in view of the psychological state of the controllers in actual work. Make it have reasonable goal expectation and long-term motivation, teach students in accordance with their aptitude, and adjust the training plan to make the training more targeted and effective.

\section{Implementation of Aviation Control Vocational Education}

\subsection{Raising Awareness of Professional Education.}

The training of controllers should aim at improving students' practical skills and responsiveness. At present, in most of the developed countries in the world, the training of controllers mostly implements the vocational education mode, pays attention to the training of practical and applied skills, and basically realizes the zero distance between teaching and production posts in Colleges and universities. After graduation, students only need a short pre-job training, or even can enter the control posts directly after graduation [5].The training of air traffic controllers in China should also draw on their successful experience and attach importance to vocational education of air traffic controllers. The education of air traffic controllers should adopt the mode of combining diploma education with vocational education. The skill training center of air traffic controllers should be established. The basic theory of air traffic control should be educated and simulated according to the needs of the front-line control units. Machine training and on-the-job teaching should be effectively combined. The teaching of basic theory of regulation should be based on the principle of post demand. Simulator training should be centered on improving control skills. On-the-job teaching should aim at the actual work demand. The gap between the education and training in Colleges and universities and the actual demand for control work should be minimized to achieve the goal of personnel training and training. Control the zero distance between job demands.

\subsection{Strengthening the Construction of Teaching Staff.}

Aviation control training plays an important role in discovering potential safety hazards in advance, enhancing the safety awareness of controllers, and improving the professional skills and psychological quality of controllers. The particularity of the education of air traffic controllers requires that the teachers of this major not only have solid theoretical knowledge, but also have rich practical experience in air traffic control. Therefore, we must build a strong team of teachers, education and training to high-quality, diversified team of teachers as a support, strengthen the training of guidance. In general, the aviation control professional teachers should be composed of professional and technical experts, safety inspectors, senior technicians and other personnel.

\subsection{Make full Use of Information Educational Resources.}

In terms of information construction, we should strengthen the overall planning and pay attention to the complementarity of information resources. A large number of teaching resources, procedures and manuals of air traffic control are digitalized. With the campus network and even the whole army network as the platform, using the network multimedia technology, the characteristics of abstraction, complexity, operability and procedural in teaching can be displayed intuitively, and the distance between air-to-ground teaching and field teaching can be shortened. With the help of information technology, such as simulation and virtual reality, the simulation of real equipment is established. Through virtual learning and training environment, improve learning effect.

\subsection{Strengthening the Training of Hardware Resources.}

In our country, there is very limited investment in the training of controllers, schools can not afford to import foreign simulators, long-term use of a single classroom teaching to train controllers. The selected control teaching simulator is also independently developed in China. It has a big gap with the control equipment used by the first-line control units, and can not guarantee the quality of personnel 
training from hardware. Therefore, China Airlines needs to continuously increase the investment in the training of controllers, from the hardware to ensure the quality of personnel training.

\subsection{Strengthen Training Efforts to Ensure the Quality of Practice Teaching.}

In terms of skill training, it is necessary to strengthen the training of controllers in procedural control, special circumstances and large flow situations, to overcome the patterning of control work, so that when faced with unexpected problems, failures and dangerous situations, controllers should have clear thinking, quick response, appropriate measures and reduce human errors.

\subsection{Establish a Long-term Mechanism for Training with a Scientific and Reasonable System as a Guarantee.}

It can promote the development of teaching quality and effect, and at the same time, it can play a role of standardization and restraint by fixing the existing laws and understanding in the vocational education of air traffic control and our practical work and establishing a scientific and reasonable system.

\section{Conclusion}

As a kind of special occupation and post education, what kind of training mode and way should be adopted, what kind of education content should be set up, and what kind of talents can be trained to meet the needs of rapid development of aviation are the key issues to be considered in promoting the development of aviation control industry. What kind of training should be organized is the most scientific and effective one, which needs to be tested by practice.

\section{References}

[1] Mengyun Wei. China Civil Aviation Air Traffic Control Professional Ethics Research, Science and Technology Wind [J]. 2014(13)247

[2] Qian Dong. Air Traffic Controller Professional Characteristics Research, Air Traffic Management [J]. 2009(3)28

[3] Xinyuan Yang. A brief analysis of the training of aviation controllers' psychological quality, technology and market [J]. 2011(3)26

[4] Xuewei Feng. Analysis of Civil Aviation Approach Control, Economic and Technical Cooperation Information [J]. 2012(23)38

[5] Danyang Li. Queue Model Analysis Method for Air Traffic Controller Workload, Air Traffic Management [J]. 2007(12)21 